\title{
Produção do conhecimento sobre as instituições especializadas para a pessoa com deficiência intelectual (1996-2015)
}

\author{
João Henrique da Silva * \\ Míriam Elena Cesar Almeida ** \\ Kátia Regina Moreno Caiado ***
}

\section{Resumo}

O presente artigo analisa a produção científica acadêmica em formato de teses e dissertações sobre as instituições especializadas para as pessoas com deficiência intelectual disponível na Biblioteca Digital de Teses e Dissertações (BDTD) do Instituto Brasileiro de Informação em Ciência e Tecnologia (IBICT). Trata-se de estudo quali-quantitativo, de abordagem metodológica bibliométrica e de análise de conteúdo, realizado em três etapas: preparação teórica e metodológica; coleta e registro de dados; sistematização e análise dos resultados. Os resultados mostram que existem 18 pesquisas sobre a temática pesquisada, a maioria de mestrado, entre os anos de 1996 a 2015. Os estudos pertencem a nove diferentes instituições de ensino superior, em sua maioria na região Sudeste e com significativa participação da Universidade Presbiteriana Mackenzie (Mackenzie) e da Universidade Federal de São Carlos (UFSCar), articuladas aos seus respectivos programas de pós-graduação: Distúrbios do Desenvolvimento e Educação Especial. Os trabalhos abordam principalmente os temas de qualidade de vida da pessoa com deficiência e a formação para o trabalho e a vida, desenvolvidos nas próprias instituições especializadas. Predominam as abordagens qualitativas com fundamentos da teoria comportamental, com base nos instrumentos de entrevistas e escalas, entre outros. O mapeamento dos estudos evidencia poucas pesquisas que focam a própria instituição especializada para a pessoa com deficiência intelectual como objeto de estudo, apesar de os trabalhos contemplarem as dimensões da saúde, trabalho, educação e assistência. Porém não encontramos pesquisas que problematizem, dentre outros: o papel de escola especial que as instituições assumem; o direito à escolarização da pessoa com deficiência; a relação público-privado que constitui a oferta dos serviços em caráter privado filantrópico e não público.

Palavras-chave: Instituição especializada. Produção do conhecimento. Educação Especial. Deficiência intelectual.

* Mestre em Educação pela Universidade Federal da Grande Dourados (UFGD).

** Mestre em Educação pela Universidade Federal de São Carlos (UFSCar). Professora da Secretaria de Educação do Estado de São Paulo (SEESP).

*** Doutora em Educação pela Universidade de São Paulo (USP). Professora do Centro de Ciências Humanas e Biológicas da Universidade Federal de São Carlos (UFSCar). 


\section{Introdução}

As instituições especializadas são protagonistas na prestação de serviço assistencial para as pessoas com deficiência. As primeiras instituições públicas foram o Instituto Benjamim Constant (1854) e o Instituto Nacional de Educação dos Surdos (1857). O período entre o final do século XIX e início do XX contou com iniciativas isoladas por parte do Estado. Nesse cenário, ocupou papel importante a psicóloga russa Helena Antipoff, que proporcionou serviço assistencial para os considerados "excepcionais" da época, criando instituições voltadas a esse público, como a Sociedade Pestalozzi (1932). O termo "excepcionais" contemplava crianças com excepcionalidade orgânica e social: os desajustados da sociedade, os abandonados, entre outros indivíduos que não se enquadravam na conduta exigida pela norma estabelecida (RAFANTE, 2011).

Antipoff também incentivou a criação da Associação de Pais e Amigos dos Excepcionais (Apae), instituição filantrópica criada em 11 de dezembro de 1954 no Rio de Janeiro, por iniciativa de familiares e amigos de pessoas com deficiência. A Apae, que completou 60 anos no final de 2014, tem por objetivo principal "promover a atenção integral à pessoa com deficiência, prioritariamente aquela com deficiência intelectual e múltipla” (FENAPAES, 2014, p. 46).

Em 1962, foi criada a Federação Nacional das APAES (Fenapaes), que, por meio de investimento do Poder Público, expandiu as unidades apaeanas por todo o país. A Fenapaes consiste em uma agremiação de 2.156 unidades, coordenadas por 24 Federações Estaduais. A agremiação abrange todos os estados brasileiros e atende, diariamente, cerca de 250 mil pessoas com deficiência intelectual e múltipla (FENAPAES, 2016). Somente Roraima não possui nenhuma instituição, pois lá a Educação Especial está presente, desde 1976, como ação governamental custeada e gerida com recursos públicos no âmbito dos sistemas educacionais (SIEMS-MARCONDES, 2013).

A Federação Nacional das Associações Pestalozzi (Fenapestalozzi) surgiu em 1970, por iniciativa da Helena Antipoff, e foi concretizada na liderança de Lizair Guarino, com o objetivo de fortalecer o movimento pestalozziano no país, principalmente no período dos anos 1970, caracterizado pela aliança entre o governo e os tecnocratas e pela presidência do país nas mãos do General Médici. Para Lizair, o propósito da Fenapestalozzi era de “[...] obter soluções cristãs e humanas para o excepcional” (THAMSTEN, 1999, p. 78). Hoje, a Fenapestalozzi conta 178 Associações Pestalozzi e diversas entidades análogas em 20 estados do país (FENAPESTALOZZI, 2015).

Valendo-se do instrumento de intervenção social, a Fenapaes e a Fenapestalozzi foram ganhando espaço na política de atendimento à pessoa com deficiência no país; por consequência, o 
"[...] crescente aumento de organizações desta natureza contribuiu, sobremaneira, para a conquista dos direitos legais da pessoa com deficiência, uma vez que passaram a exercer o papel de instigadoras do Estado"(D’ANTINO, 1998, p. 41).

Tal papel de instigadoras do Estado deu-se à medida que a Fenapaes e a Fenapestalozzi se constituíam como espaços de cooperação, gerenciamento e influência para a implementação de políticas. Esse papel condiz com o ideário liberal e neoliberal que permeia os discursos das políticas educacionais, nas quais os direitos tornam-se prestações de serviços paliativos e assistencialistas. Tais serviços são ofertados pelas Apaes porque há uma concepção difundida de que essas entidades são ações do Poder Público. Na verdade, as Apaes são sociedades civis que compõem a dinâmica política do Estado brasileiro. O Estado, em sentido estrito, obtém vantagens em transferir recursos e fundos para as entidades, pois assim não necessita construir políticas públicas sociais consistentes e sistemáticas.

Desse modo, ambas as federações - Fenapaes e Fenapestalozzi - conquistaram reconhecimento da sociedade civil por prestarem serviços na área da saúde, educação, trabalho e assistência social para as pessoas com deficiência intelectual (FENAPAES, 2014; JANNUZZI; CAIADO, 2013; THAMSTEN, 1999).

Aliás, para D’Antino (1998), as instituições são palco de experiências e fonte de aprendizado e inquietações. Elas são, concomitantemente, produtos e produtoras da ação de sujeitos que a constituem, e "[...] os sujeitos que a constituem são, ao mesmo tempo, os instituintes e instituídos da estrutura e do funcionamento institucional” (D’ANTINO, 1998, p. 29). Ou seja, as instituições interferem significativamente nas dimensões da vida da pessoa com deficiência.

Tendo presente esse cenário, investigamos, inicialmente, a produção científica acadêmica teses e dissertações produzidas no Brasil - sobre a temática das instituições especializadas no campo da Educação Especial disponível na Biblioteca Digital de Teses e Dissertações do Instituto Brasileiro de Informação para Ciência e Tecnologia (BDTD/IBICT).

O primeiro levantamento de trabalhos resultou em 57 estudos relacionados às instituições especializadas para a pessoa com deficiência, distribuídos no formato de 46 dissertações (mestrado) e 11 teses (doutorado), divulgadas no período de 1994 a 2015, concentradas no triênio 2009-2011.

Os pesquisadores ${ }^{1}$ identificados fazem parte de 16 instituições, e a maioria das pesquisas se concentra nos programas de pós-graduação da Universidade Presbiteriana Mackenzie (Mackenzie) (21\%), da Universidade Estadual de Campinas (Unicamp) (14\%), da Universidade Federal de São Carlos (UFSCar) (14\%) e da Universidade de São Paulo (USP) (12\%). Inclusive, grande parte das 
instituições encontram-se no Sudeste, são públicas (federais e estaduais) e abrangem programas de pósgraduação no campo da Educação $(n=27)$, Psicologia $(n=8)$, Saúde $(n=5)$, na interdisciplinaridade da Psicologia, Saúde e Educação $(n=11)$, entre outras áreas. Como indicam Pereira, Júnior e Hayashi (2013), as regiões Sudeste e Sul possuem a maior concentração de programas de pós-graduação no país, inclusive a região Sudeste possui programas de pós-graduação strictu sensu e linhas de pesquisas relacionas à Educação Especial, com destaque para as universidades Mackenzie e UFSCar, nas quais há mestrado e doutorado específico na área (Distúrbios do Desenvolvimento e Educação Especial).

As temáticas estão voltadas para a relação entre educação, deficiência, inclusão escolar e social e o papel da família. Essas temáticas indicam a preponderância das pesquisas que se ocupam da área da educação e dos diversos tipos de deficiência e transtornos globais do desenvolvimento. Na verdade, as temáticas contemplam a maioria do atual público-alvo da Educação Especial (BRASIL, 2008), com exceção de alunos com altas habilidades/superdotados: deficiência intelectual ( $n=18)$, deficiência visual $(n=12)$, transtornos globais do desenvolvimento/autismo $(n=8)$, deficiência física $(n=6)$, deficiência auditiva $(n=1)$, múltiplas deficiências $(n=1)$, surdocegueira $(n=1)$ e transtornos funcionais específicos $(\mathrm{n}=1)$. Nota-se também escassez de estudos sobre instituições especializadas para pessoas surdas, surdocegas, com múltiplas deficiências e transtorno de déficit de atenção e hiperatividade (TDAH). O foco deste artigo são as 18 pesquisas que versam sobre as pessoas com deficiência intelectual nas instituições especializadas.

É importante mencionar que, do total de 57 estudos coligidos, 38 trabalhos foram realizados nas instituições especializadas e 19 versaram sobre a atuação dessas instituições, de forma direta ou não, na esfera da vida social e política nos serviços prestados às pessoas com deficiência. Esse dado revela que as instituições especializadas constituem, na área da Educação Especial, mais uma fonte de coleta de dados, enquanto poucos estudos se debruçam sobre a mediação promovida pelas instituições na vida das pessoas com deficiência ou ainda sobre a promoção de políticas públicas.

Os dezenove trabalhos abordam sete diferentes eixos temáticos, quais sejam: a) representações, significados e discursos sobre a deficiência; b) trajetória das pessoas com deficiência que frequentaram instituições especializadas; c) formação continuada de professores em Educação Especial no estado de Santa Catarina; d) programas de apoio e intervenção desenvolvidos nas instituições e avaliação da participação dos alunos e pais; e) capacitação profissional e inserção no mercado de trabalho das pessoas com deficiência; f) política e história da Educação Especial em municípios e estados e a participação de Helena Antipoff e das Sociedades Pestalozzi na constituição do campo da Educação 
Especial no Brasil; g) processos educacionais do público-alvo da Educação Especial, relacionados às representações, às concepções de aprendizagem e aos programas de apoio à inclusão escolar.

As diversidades dos objetivos procuraram compreender de que forma as atitudes e serviços das entidades mediam a vida do público atendido, suas famílias e o mercado de trabalho. Os objetivos mostram que as instituições especializadas ocupam um papel significativo no desenvolvimento das capacidades e habilidades para a vida diária e para a inserção no trabalho. Os pais são parceiros desse processo, uma vez que a responsabilidade no cuidado dos filhos recai sobre eles. Os objetivos também abordam diferentes contextos sociopolíticos e educacionais, bem como de implementações de políticas educacionais em diferentes municípios e estados que, por sua vez, contam com trajetórias educacionais peculiares que interferem na tradução dessas políticas. Os dados coletados também evidenciam que as instituições especializadas se organizam para atender diferentes públicos, principalmente as pessoas com deficiência intelectual e síndrome de Down, os quais estiveram presentes, respectivamente, em onze e sete produções.

Essa complexidade de dados suscitou a seguinte questão norteadora: como se configuram os estudos oriundos da produção científica acadêmica da pós-graduação brasileira que abordam a temática das instituições especializadas para as pessoas com deficiência intelectual?

Portanto, o presente artigo tem o objetivo de analisar a produção científica acadêmica disponível na BDTD/IBICT - teses e dissertações produzidas no Brasil - sobre a temática das instituições especializadas para as pessoas com deficiência intelectual. Também visa à identificação e à caracterização das 18 pesquisas selecionadas a partir do levantamento realizado, conforme os seguintes parâmetros bibliométricos: autoria, orientação, perfil do pesquisador e do orientador, nível de estudos, configuração institucional, temporal e geográfica dos trabalhos, classificação das áreas do conhecimento, mapeamento das temáticas e dos tipos de pesquisa. Por último, analisa os resultados obtidos na temática investigada.

\section{Metodologia}

A pesquisa foi conduzida mediante a adoção da abordagem bibliométrica e da análise de conteúdo. A bibliometria pauta-se pelo princípio de analisar a atividade científica ou técnica pelos estudos quantitativos das publicações. Por meio dessa abordagem, “os dados quantitativos são calculados a partir de contagens estatísticas de publicações ou de elementos que reúnem uma série de técnicas estatísticas, buscando quantificar os processos de comunicação escrita" (SILVA; HAYASHI; 
HAYASHI, 2011, p. 113). Sacardo (2012, p. 18) complementa esse entendimento ao considerar que os estudos bibliométricos são úteis para mapear um campo científico, avaliar a pesquisa acadêmica, "[...] bem como para orientar rumos e estratégias de financiamento de pesquisas e apontar o alcance analítico para o estudo de um campo científico".

Todavia, embora as análises bibliométricas sejam frequentemente associadas às suas características quantitativas, em virtude dos recursos matemáticos que dão suporte a essa metodologia, consideramos que é preciso ultrapassar essa visão, pois, como argumentam Hayashi, Hayashi e Martinez (2008, p. 139), “as estatísticas não constituem um fim em si mesmas, mas são mobilizadas para analisar a dimensão coletiva da atividade de pesquisa e o processo dinâmico da construção de conhecimentos".

Nesse aspecto, concordamos com os argumentos de Gatti (2001), que enfatiza não haver dissociação entre os conceitos de qualidade e quantidade, uma vez que a quantidade precisa ser interpretada qualitativamente.

Desse modo, a utilização da análise de conteúdo tem se revelado um método eficaz para complementar os estudos bibliométricos, pois permite extrair o sentido dos textos por meio de unidades e categorias de análise.

Os procedimentos metodológicos adotados foram desenvolvidos conforme as seguintes etapas:

1) Fase de preparação teórica e metodológica, por meio da qual foram definidas as seguintes expressões de busca para coleta de dados, instituição(ões) especializada(s) (no singular e no plural);

2) Fase de coleta e registro de dados, de acordo com o protocolo de registro de dados bibliométricos (HAYASHI, 2014), utilizando o software Microsoft Excel ${ }^{\circledR}$.

Em seguida, construímos outro protocolo para analisar a produção acadêmica sobre a instituição especializada para a pessoa com deficiência intelectual ou mental. O protocolo foi adaptado para contemplar o balanço preliminar de Bueno (2008) sobre as dissertações e teses relacionadas ao aluno com deficiência no Ensino Superior, com base nas seguintes questões: "De onde e quando foram narrados? Sobre o que e de que forma incidem a narrativas? (BUENO, 2008, p. 2). E, por último, a terceira fase, de sistematização e análise dos resultados, abrangeu a organização, o tratamento bibliométrico e a análise dos dados coletados.

É importante informar que realizamos a leitura dos títulos dos trabalhos, dos resumos e dos textos integrais, o que deu condições de verificar a presença ou a ausência do enfoque sobre a instituição especializada e pessoa com deficiência intelectual. 


\section{Instituição especializada e deficiência intelectual: balanço das dissertações e teses brasileiras (1996-2015)}

Verificamos que, na temática investigada, há dezesseis dissertações e duas teses. Isso expressa um número reduzido de trabalhos acerca da temática analisada, apesar de existir um grande contingente de instituições especializadas voltadas para o público em questão.

No banco de dados da Plataforma Sucupira (2017), quanto à relação de cursos recomendados e reconhecidos pela Coordenação de Aperfeiçoamento de Pessoal de Nível Superior (Capes) até o ano de 2016, consta que existem 4.381 programas de pós-graduação nas cinco regiões brasileiras: 1.376 programas de mestrado, 82 de doutorado, 781 de mestrado profissionalizante, 2.136 programas com mestrado e doutorado. Assim, a situação da pós-graduação no país oferece muito mais cursos de mestrado do que de doutorado, com tempo de duração mais curto e mais vagas oferecidas, o que explica a maior produção de dissertações (PEREIRA; JÚNIOR; HAYASHI, 2013).

Outros fatores que podem explicar o grande número de cursos de mestrado e de doutorado são as pluralidades de funções na formação acadêmico-profissional e o fato de que "[...] nem todas as universidades são universidades de pesquisa, e as que o são não fazem toda a pesquisa com a mesma intensidade [...], assim como nem todas são de pós-graduação, e as que o são não a fazem da mesma forma" (STEINER, 2005, p. 345).

Na produção acadêmica coletada, identificamos que cada autor realizou um tipo de pesquisa, orientado por onze professores pesquisadores diferentes. Houve três professores pesquisadores que orientaram mais de um trabalho, a saber: Prof. ${ }^{a}$ Dr. ${ }^{a}$ Silvana M. Blascovi de Assis (Mackenzie), com três pesquisas; Prof. Dr. Antônio C. de N. Goyos e Prof. ${ }^{a}$ Dr. ${ }^{a}$ Maria da Piedade R. da Costa, com dois estudos cada um, ambos da UFSCar.

A produção acadêmica levantada compreende o período de 1996 a 2015. Constatou-se que não houve publicação sobre a referida temática nos anos de 1999 a 2005, 2007, 2010 e 2014. A produção analisada revela que as pesquisas sobre as instituições especializadas para a pessoa com deficiência intelectual são incipientes, como podemos ver no Gráfico 1, que demonstra um silenciamento da produção sobre a temática em um período de seis anos ininterruptos. A produção sobre a temática em questão aumenta em 2009, depois fica ausente, mas retoma o crescimento e permanece equilibrada entre 2011 e 2013. 
A presente configuração temporal indica que a ausência de pesquisas pode estar relacionada ao número de programas de pós-graduação, bem como ao fato de as instituições especializadas prestarem um serviço de filantropia. Este corresponde a um trabalho social que instiga solidariedade às pessoas com deficiência, mas não consiste na defesa dos direitos sociais que devem ser garantidos pelo Estado. Inclusive, a produção incipiente entre 2003 e 2008 indica que, talvez, a quantidade de pesquisas esteja relacionada à implementação do Programa "Educação Inclusiva", do governo federal.

Gráfico 1 - Configuração temporal por nível de pesquisa

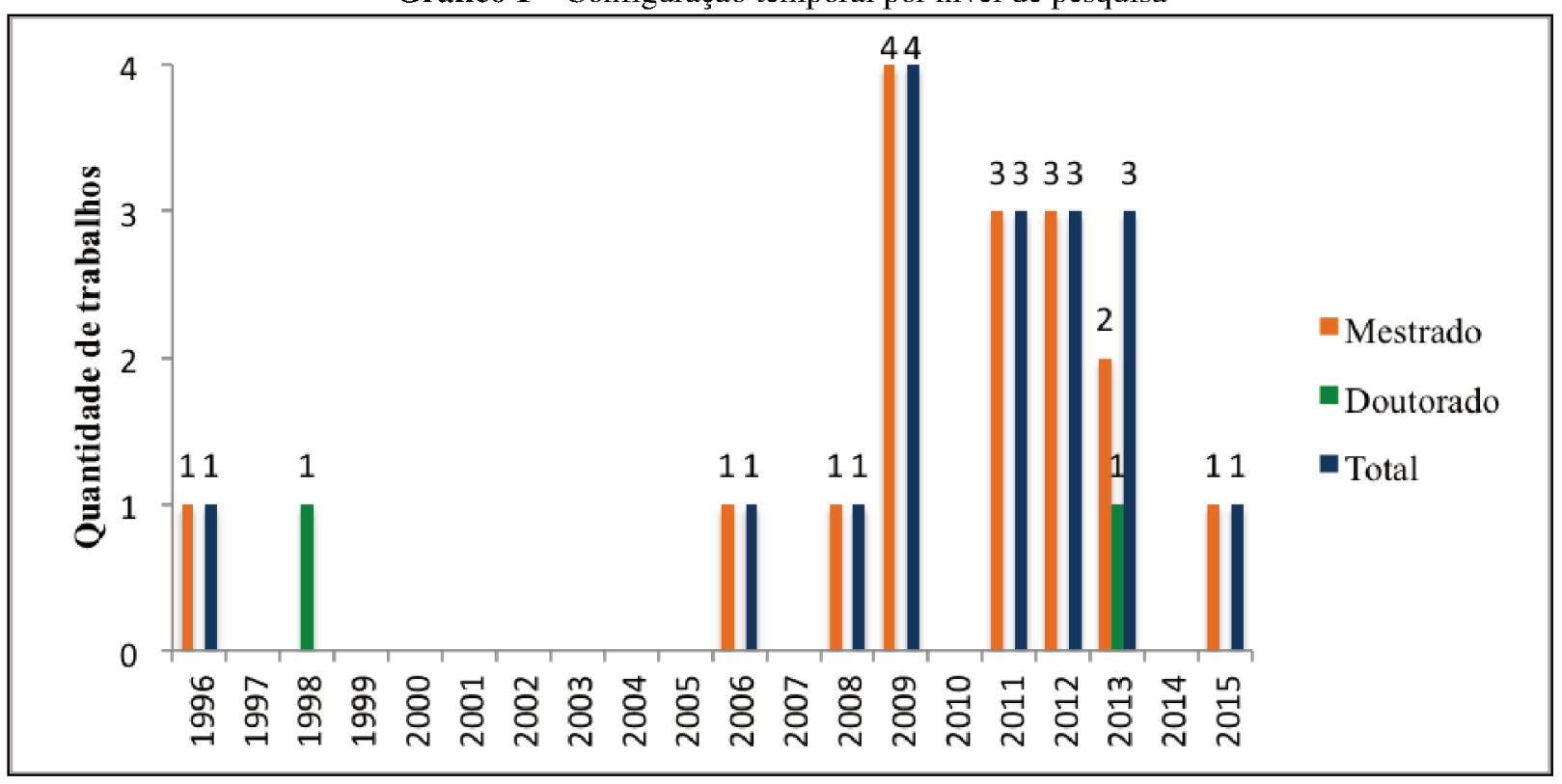

Fonte: Dados coletados na BDTD/IBICT, 2015.

A política da Educação Especial começou a ser modificada a partir de 2003, quando o governo federal implementou a política de "Educação Inclusiva", que faz parte de uma agenda internacional, proposta por organismos multilaterais. Essa política objetiva matricular todas as crianças com deficiência nas escolas regulares. Ou seja, o serviço educacional substitutivo não poderia continuar persistindo nas políticas brasileiras. A formulação inicial da Política Nacional de Educação Especial na Perspectiva da Educação Inclusiva (PNEE-PEI), em 2007, e o Decreto $\mathrm{n}^{\mathbf{0}} 6.571$, de 17 de dezembro de 2008, determinavam que o atendimento educacional especializado (AEE) fosse ofertado na rede pública regular de ensino, e o Ministério da Educação prestaria apoio técnico e financeiro para concretizá-lo, por meio do Fundo de Manutenção e Desenvolvimento da Educação Básica e de Valorização dos Profissionais da Educação (Fundeb). Esses documentos geraram reações controversas por parte das instituições privadas-assistenciais. Instituições como as Apaes perderiam o repasse dos 
recursos. A Fenapaes (2007), então, posicionou-se de forma contrária aos documentos, pleiteando a permanência das escolas especiais.

O documento da PNEE-PEI foi reformulado, e o Decreto 6.571/2008 foi revogado pelo Decreto n 7.611 , de 17 de novembro de 2011. Este decreto fez uma alteração sutil, mas fundamental. O inciso VII do art. $1^{\circ}$, que trata do dever do Estado com a educação das pessoas público-alvo da Educação Especial, prescreve que essa educação será efetivada também pela "oferta de educação especial preferencialmente na rede regular de ensino" (BRASIL, 2011).

Como analisaram Melo e Silva (2016, p. 158), a legislação mostra o jogo de forças ligado à Educação Especial, e o retorno do termo "preferencialmente" indica uma tentativa do Ministério da Educação (MEC) em buscar consensos, mas enfrenta pressões de grupos atuantes no Congresso Nacional e no governo federal em prol das instituições especializadas.

Presente essa disputa pela hegemonia no campo da Educação Especial, foram necessárias novas pesquisas a fim de compreender a realidade das instituições especializadas para pessoas com deficiência intelectual. Talvez, por essas razões, o número de pesquisas tenha crescido entre 2011 e 2013.

Constatamos que as dezoito produções estão vinculadas a nove instituições de ensino superior, o que representa a média de duas produções por instituição. A Tabela 1 apresenta a distribuição das instituições por número de trabalhos defendidos. Por um lado, esse dado mostra que o tema tem se disseminado pelos programas de pós-graduação no Brasil. Por outro lado, também revela uma dispersão de estudos que não implica, necessariamente, em acúmulo de conhecimento.

Tabela 1 - Configuração dos trabalhos por instituição

\section{Instituições}

Total de

trabalhos

$$
\begin{gathered}
\text { Universidade Presbiteriana Mackenzie (Mackenzie) } \\
\text { Universidade Federal de São Carlos (UFSCar) } \\
\text { Universidade Estadual de Campinas (Unicamp) }
\end{gathered}
$$

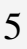

4

3

6

Salvador (UCS), Universidade do Estado do Rio de Janeiro (Uerj), Universidade

Estadual de São Paulo (Unesp), Universidade Federal do Maranhão (UFMA), Universidade de São Paulo (USP) (n=1)

\section{Total} 18

Fonte: Organizada pelos autores com dados colhidos em BDTD/IBICT (2015). 
A Tabela 1 mostra a concentração dos estudos na Mackenzie, na UFSCar e na Unicamp, os quais, somados, correspondem a 66,7\% do total de trabalhos localizados. A distribuição anual dos estudos por instituição demonstra a não consolidação da pesquisa sobre a referida temática nos programas de pós-graduação, como vemos na Tabela 2.

A produção acadêmica da temática em questão é marcada por rupturas e descontinuidades. Somente a Mackenzie e a UFSCar demonstram certa continuidade nesse foco de pesquisa, que, por sua vez, encontra-se rarefeito em outras instituições.

Tabela 2 - Distribuição anual por instituição e ensino superior entre os anos de 1996 a 2015

\begin{tabular}{|c|c|c|c|c|c|c|c|c|c|}
\hline \multirow{2}{*}{ Ano } & \multicolumn{9}{|c|}{ Instituição } \\
\hline & Mackenzie & PUC-RJ & UCS & UERJ & UFMA & UFSCar & Unesp & Unicamp & USP \\
\hline 1996 & - & - & - & - & - & - & - & 1 & - \\
\hline 1997 & - & - & - & - & - & - & - & - & - \\
\hline 1998 & - & - & - & - & - & - & - & 1 & - \\
\hline 1999-2005 & - & - & - & - & - & - & - & - & - \\
\hline 2006 & 1 & - & - & - & - & - & - & - & - \\
\hline 2007 & - & - & - & - & - & - & - & - & - \\
\hline 2008 & 1 & - & - & - & - & - & - & - & - \\
\hline 2009 & - & - & 1 & - & - & 2 & - & - & 1 \\
\hline 2010 & - & - & - & - & - & - & - & - & - \\
\hline 2011 & 1 & 1 & - & - & - & 1 & - & - & - \\
\hline 2012 & - & - & - & 1 & 1 & - & - & 1 & - \\
\hline 2013 & 2 & - & - & - & - & 1 & - & - & - \\
\hline 2014 & - & - & - & - & - & - & - & - & - \\
\hline 2015 & - & - & - & - & - & - & - & - & - \\
\hline Total & 5 & 1 & 1 & 1 & 1 & 4 & 1 & 3 & 1 \\
\hline
\end{tabular}

Fonte: Elaborada pelos autores a partir da produção acadêmica coletada.

Nota: Sinal convencional utilizado:

- Valor numérico igual a zero não proveniente de arredondamento.

Acrescentamos que as pesquisas coletadas foram produzidas, em sua maioria, por instituições públicas (seis instituições, com onze trabalhos), ao passo que as três instituições privadas produziram sete estudos. Entre as primeiras, ressaltamos as estaduais, com seis produções, e as federais, com cinco trabalhos, ou seja, elas foram responsáveis por mais da metade da produção $(61,1 \%)$, enquanto as privadas, com três instituições, participaram, de modo representativo, com 38,9\% dos trabalhos. 
Aliás, cabe acrescentarmos que as pesquisas também foram desenvolvidas principalmente na região Sudeste (sete instituições, com dezesseis produções) e, com pouca expressividade, na região Nordeste (duas instituições, com um trabalho cada). A Plataforma Sucupira (2017) revela que as regiões Sudeste e Sul possuem a maior concentração de programas de pós-graduação do país, qual seja, 1.952 e 937 programas, respectivamente. Também é preciso considerar que o Sudeste possui 831 unidades apaeanas, o equivalente a aproximadamente 40\% das 2.156 Apaes distribuídas no território nacional (FENAPAES, 2015). Além disso, existem 69 Associações Pestalozzi no Sudeste (FENAPESTALOZZI, 2015). No entanto, por que a região Sul não teve produção na temática analisada? Por que poucas pesquisas foram realizadas na região Sudeste, onde predomina o complexo de serviços para as pessoas com deficiência intelectual e múltipla? São questões de ordem sociopolítica, econômica e educacional que merecem novos estudos.

As dezoito pesquisas foram financiadas por três agências de fomento, a saber: Capes, com quatro trabalhos; Mackpesquisa, com três estudos; e o Conselho Nacional de Desenvolvimento Científico e Tecnológico (CNPq), com duas pesquisas. Outras nove produções não mencionaram a agência. Isso indica que, apesar de poucas pesquisas $(n=6)$ realizadas por agências ligadas ao governo federal, ele tem contribuído para o financiamento das produções acadêmicas. A Mackenzie também parece investir na formação do pesquisador.

Ademais, as produções acadêmicas foram defendidas em diferentes programas de pósgraduação, como pode ser observado na Tabela 3:

Tabela 3 - Configuração das áreas dos Programas de Pós-Graduação

\begin{tabular}{ccc}
\hline Programa & Quantidade & Frequência relativa (\%) \\
\hline Distúrbios do Desenvolvimento & 5 & 27,8 \\
Educação Especial & 3 & 16,8 \\
Educação & 2 & 11 \\
Educação Física & 2 & 11 \\
Psicologia & 2 & 11 \\
Enfermagem em Saúde Pública & 1 & 5,6 \\
Saúde Materno-Infantil & 1 & 5,6 \\
Serviço Social & 1 & 5,6 \\
Políticas Sociais e Cidadania & 1 & 5,6 \\
\hline Total & $\mathbf{1 8}$ & $\mathbf{1 0 0}$ \\
\hline
\end{tabular}

Fonte: Organizada pelos autores com dados coletados em BDTD/IBICT (2015). 
A Tabela 3 revela que o Programa de Pós-Graduação em Distúrbios do Desenvolvimento teve uma significativa contribuição na temática estudada. Esse programa faz parte da área de concentração que abrange a Psicologia, a Educação e a Saúde (MACKENZIE, 2015). Talvez essa configuração seja a responsável pelos estudos terem sido realizados em instituições especializadas, visto que elas prestam serviços assistenciais articulados à área de concentração do programa.

O Programa de Pós-Graduação em Educação Especial também foi responsável pela produção acadêmica. Este programa é “[ ...] duplamente pioneiro: por ser o primeiro Programa de Pós-Graduação em Educação Especial implantado no país e por constituir-se no único programa específico na área" (SILVA, 2004, p. 17). No geral, observamos que as pesquisas sobre instituições especializadas foram desenvolvidas, principalmente, no campo da Educação (sete trabalhos ou 38,8\% do total). Luiz et al. (2008) destacam que os profissionais da educação também foram os que mais produziram sobre a inclusão escolar de crianças com síndrome de Down. Inclusive, a produção científica sobre inclusão escolar de pessoas com deficiência mental, no formato de artigos, concentra-se principalmente na área educacional (BARBOSA; MOREIRA, 2009).

Ademais, os estudos de instituições especializadas para pessoas com deficiência também se fizeram presentes em outros campos do conhecimento, como na Psicologia, na Saúde, nas Ciências Sociais Aplicadas e na Sociologia (ciências humanas). A interface das pesquisas com outras áreas e disciplinas pode contribuir na formulação de conhecimentos científicos para o avanço temático e metodológico dos estudos. Mas, como diz Bueno (2008), era esperado que a maior concentração de pesquisas estivesse em programas da área da Educação.

Por isso, procuramos extrair as temáticas das dezoito pesquisas, objetivando compreender os temas frequentes ou poucos explorados. O Quadro 1 expõe a diversidade de temas a respeito da pessoa com deficiência intelectual.

Quadro 1 - Temas principais das produções acadêmicas coletadas (continua)

\begin{tabular}{|c|c|c|}
\hline Tema & Autores & Quantidade \\
\hline Qualidade de vida da pessoa com deficiência & $\begin{array}{c}\text { Macedo (2011), Winter de Morais (2011), } \\
\text { Silva (2012), Rezende (2013) e Carrogi- } \\
\text { Vianna (2013) }\end{array}$ & 5 \\
\hline Formação para o trabalho e a vida & $\begin{array}{c}\text { Rodrigues (1998), Gomes de Sousa (2011), } \\
\text { Carvalho Mascaro (2012) e Dota (2015) }\end{array}$ & 4 \\
\hline Desenvolvimento psicomotor e de linguagem & $\begin{array}{c}\text { Oliveira Capote (2009), Chereguini (2009) e } \\
\text { Doriqui (2012) }\end{array}$ & 3 \\
\hline Leitura e escrita & Hein (2006) e Comin (2013) & 2 \\
\hline
\end{tabular}


Quadro 1 - Temas principais das produções acadêmicas coletadas (conclusão)

\begin{tabular}{|c|c|c|}
\hline Tema & Autores & Quantidade \\
\hline Inclusão escolar & Duque (2008) e Faria Linhas (2009) & 2 \\
\hline Concepções e representações da deficiência & Rojas (1996) & 1 \\
\hline Relação Família-Escola & Luiz (2009) & 1 \\
\hline \multicolumn{2}{|c|}{ Total } & $\mathbf{1 8}$ \\
\hline
\end{tabular}

Fonte: Elaborado pelos autores com dados presentes nas pesquisas acadêmicas analisadas.

No Quadro 2 fica demonstrado que as pesquisas realizadas nas instituições especializadas possuem diferentes focos, entre os quais ressaltamos os temas voltados para a qualidade de vida do público atendido, uma vez que a condição da deficiência implica constante prevenção (secundária e terciária) e cuidados com a saúde. A formação para o trabalho e a vida também é um tema privilegiado, pois o processo de transição instituição-trabalho requer preparar os jovens para o mercado de trabalho, porém questionamos com qual objetivo é desenvolvida essa qualificação. Inclusive, poucos estudos estão voltados para as condições do ensino-aprendizagem. Os trabalhos analisaram o processo de aquisição de leitura e escrita, mas não avançaram no propósito de compreender de que forma as crianças e jovens com deficiência podem se apropriar do conhecimento científico, artístico e filosófico. A compilação dos dados sugere que a contribuição desses trabalhos se deve ao fato de a criança com a Síndrome de Down manifestar comprometimento no desenvolvimento da linguagem (LUIZ et al., 2008). Não se trata de desmerecer o trabalho das instituições para o desenvolvimento psicomotor e da linguagem, mas procuramos problematizar de que forma as crianças e jovens com deficiência intelectual podem se desenvolver no âmbito da educação escolar.

Vygotski (1997) salienta que a deficiência é um estado normal, não patogênico, que resulta da forma como a pessoa com deficiência reflete sobre suas próprias experiências sociais. A deficiência é um conceito social. Ela é o ponto de partida e a principal força motriz de desenvolvimento psíquico da personalidade do ser humano. A criança com deficiência pode alcançar tudo o que outra criança sem deficiência pode alcançar, mas por outros meios (VYGOTSKI, 1997).

As temáticas de pesquisas têm como escopo "a deficiência", e não o desenvolvimento qualitativo e diferenciado de cada sujeito. Grande número de trabalhos relacionados à qualidade de vida está vinculado à perspectiva biologista da deficiência, segundo a qual as pessoas estariam limitadas por causa das suas estruturas orgânicas, e a melhoria dessas estruturas poderia levá-las a progredir. Aliás, a qualidade de vida é um princípio assegurado pela sociedade neoliberal, porque possibilita à pessoa com deficiência inserir-se no movimento mais amplo de reordenações do sistema 
produtivo. A pretensa qualidade de vida atribuída, nos estudos, à pessoa com deficiência visa à adaptação do sujeito à sociedade.

Os temas de pesquisa podem estar associados, inclusive, ao fato de as instituições especializadas ou privadas-assistenciais se apresentarem como independentes e neutras em relação a qualquer projeto societário. Martins e Groppo (2010) expõem que a sociedade civil é significada de forma diferente e inovadora no século XXI. Ela é compreendida como "iniciativa social ou como setor, um espaço, neutro ético-política e ideologicamente, isto é, nem comprometido com o capitalismo [...], nem, muito menos, com o socialismo" (MARTINS; GROPPO, 2010, p. 121). As instituições privadasassistenciais são vistas como um "bom” espaço público de formação para as pessoas com deficiência intelectual, que se diferencia da escola tradicional, que não é adequada ao público com deficiência. Na verdade, a sociedade civil, representada pelas instituições, “[...] tem comprometimento político e ideológico, e, ademais, tal compromisso é com um projeto conservador” (MARTINS; GROPPO, 2010, p. 123).

Desse modo, há manutenção no aspecto de formação educacional básica e assistencialista, em conformidade aos princípios filantrópicos, e não aos de empoderamento e de exercício da cidadania ativa ou da formação de um cidadão, “[...] com um papel ético-político definido, qual seja, o de superar a sua condição de indivíduo para se projetar na luta política, visando transformar as estruturas e superestruturas que produzem e reproduzem as desigualdades entre as classes sociais" (MARTINS, 2000, p. 14).

Esses questionamentos acentuam-se quando identificamos que todos os estudos elegeram como campo empírico da pesquisa as próprias instituições especializadas. Somente cinco se articularam com as escolas da educação básica. Outras duas pesquisas tiveram, também, como cenário, as empresas que tinham parcerias com entidades para o ingresso do jovem. Entendemos, assim, que esses dados demonstram a repercussão intensa do processo de institucionalização na vida da pessoa com deficiência, visto que as políticas públicas garantem a parceria público-privada. Por outro lado, constatamos que quatorze trabalhos elegeram a instituição como fonte de coleta de dados, e apenas quatro trabalhos analisaram a instituição como objeto de estudo sob determinada temática (CARVALHO MASCARO, 2012; COMIN, 2013; RODRIGUES, 1998; ROJAS, 1996).

Os dezoito trabalhos envolvem diferentes tipos de pesquisas, com características específicas, bem como fundamentos teóricos e metodológicos muito distantes entre si. Desse modo, para clarear os tipos de estudos, utilizamos os termos definidos pelos pesquisadores nos resumos e, quando não foi possível, recorremos a uma leitura flutuante do texto. Os dados podem ser observados na Tabela 4: 
Tabela 4 - Tipos de pesquisa

\begin{tabular}{cc}
\hline Tipos de estudo & Quantidade \\
\hline Qualitativo & 6 \\
\hline Experimental & 4 \\
Quantitativo & 3 \\
\hline Quantitativo-qualitativo & 2 \\
\hline Descritivo & 1 \\
\hline Exploratório & 1 \\
\hline Pesquisa-ação & 1 \\
\hline Total & $\mathbf{1 8}$ \\
\hline
\end{tabular}

Fonte: Elaborada pelos autores com dados colhidos nos trabalhos acadêmicos analisados.

A Tabela 4 apresenta sete tipos de pesquisas, evidenciando que o campo da Educação Especial "[...] é multidisciplinar e incorporou pesquisas, técnicas e trabalhos de outras áreas do conhecimento para operacionalizar e desenvolver as habilidades das pessoas com necessidades especiais" (BELLO; PIZZANI; HAYSHI, 2013, p. 147). Predominam estudos qualitativos (27,8\%) e experimentais $(22,2 \%)$. Eles representam a metade dos trabalhos. Outros tipos, como o quantitativo e a sua combinação com as pesquisas qualitativas, também estiveram presentes, ainda que em poucos trabalhos. Luiz et al. (2008) entendem que os estudos qualitativos constituem uma das possibilidades para compreensão da inclusão da criança com Síndrome de Down na rede regular de ensino, por exemplo. Eles também podem ser complementados por pesquisas com abordagem quantitativa, porque explorar o processo de inclusão sob várias vertentes poderá contribuir para melhorar a compreensão dessa realidade e redirecionar novas pesquisas e intervenções, de acordo com as necessidades dos sujeitos envolvidos (LUIZ et al., 2008).

Os dados também nos mostram que, por um lado, a diversidade dos tipos de pesquisa manifesta diferentes olhares para a pessoa com deficiência. Por outro lado, as características do método interferem nas concepções e nos resultados. Mas, para verificar essas interferências, seria necessário um estudo epistemológico das produções, pois os “[...] programas são produtores, em potencial, de conhecimentos científicos, o que impõe a necessidade de uma reflexão crítica, teórica e filosófica sobre seu próprio conhecimento" (SILVA; GAMBOA, 2011, p. 376). Estudos de caráter epistemológico consistem no exame crítico-reflexivo dos processos do conhecimento humano que proporcionam analisar abordagens metodológicas, opções paradigmáticas e modos diversos de interpretar a realidade (SILVA; GAMBOA, 2011). 
Dessa maneira, optamos por levantar os procedimentos de coleta de dados utilizados pelos pesquisadores, como vemos na Tabela 5. Advertimos que, apesar de muitos deles indicarem mais de um procedimento, foram selecionados aqueles que nos pareceram centrais na investigação efetivada.

A Tabela 5 traz à baila diferentes procedimentos, que correspondem aos tipos de pesquisa já mencionados. A entrevista e as escalas têm prevalecido sobre outros procedimentos. São técnicas frequentes nos estudos qualitativos e experimentais. O diário de campo, a observação e os questionários foram empregados em três trabalhos.

Tabela 5 - Procedimentos de coleta de dados

\begin{tabular}{cc}
\hline Procedimentos & Quantidade \\
\hline Entrevistas & 9 \\
Escalas (comportamento, avaliação etc.) & 9 \\
Diário de campo & 3 \\
Observação & 3 \\
Questionários & 3 \\
Análise documental & 2 \\
\hline Total & $\mathbf{2 9}$ \\
\hline
\end{tabular}

Fonte: Elaborada pelos autores com dados obtidos a partir das pesquisas acadêmicas estudadas.

A análise documental somente esteve presente em duas pesquisas, o que evidencia que poucos estudos usaram o documento para "[...] operar um corte longitudinal que favorece a observação do processo de maturação ou de evolução de indivíduos, grupos, conceitos, conhecimentos, comportamentos, mentalidades, práticas, etc., bem como o de sua gênese até os nossos dias" (CELLARD, 2010, p. 295). In casu, trata-se da análise da organização e funcionamento da instituição especializada, bem como da prática pedagógica e das concepções de educação, deficiência e inclusão que permeiam o espaço institucional.

Por último, refletimos também sobre os principais achados dos estudos presentes no Quadro 2, que reforçam a diversidade temática:

Quadro 2 - Resultados das temáticas pesquisadas (continua)

\begin{tabular}{|c|l|}
\hline Autores & \multicolumn{1}{|c|}{ Resultados } \\
\hline Rojas & $\begin{array}{l}\text { As temáticas deste estudo referem-se às características cronológicas, físico-biológicas, } \\
\text { psicológicas e sociais, comportamentos típicos do deficiente mental e concepções sobre sua } \\
\text { condição de adulto, sua formação escolar e profissional. Foram igualmente incluídas a avaliação } \\
\text { das instituições especializadas e a pessoa deficiente mental, segundo teorias da vida adulta. }\end{array}$ \\
\hline
\end{tabular}


Quadro 2 - Resultados das temáticas pesquisadas (continuação)

\begin{tabular}{|c|c|}
\hline Autores & Resultados \\
\hline $\begin{array}{l}\text { Rodrigues } \\
\text { (1998) }\end{array}$ & $\begin{array}{l}\text { Do ponto de vista mais amplo, com relação às entrevistas dos profissionais, pudemos perceber a } \\
\text { necessidade de maiores reflexões sobre valores que incluem a preparação para o trabalho e para a } \\
\text { vida. Evidenciou-se também, de forma mais específica, algumas contradições com relação ao } \\
\text { discurso de alguns profissionais e as suas práticas institucionais, parte delas, obviamente, por } \\
\text { conta de problemas que não dependem exclusivamente do profissional, mas de toda uma estrutura } \\
\text { instalada. As entrevistas com aprendizes e egressos confirmaram a necessidade de ouvi-los: "essa } \\
\text { escola é boa porque aqui todo mundo aprende", "aqui eu tenho amigos". A ideia de que alguém } \\
\text { deve falar por eles deverá ser no mínimo repensada, ficando também evidente alguns } \\
\text { desencontros sobre o que se pensa da pessoa portadora de deficiência mental e sobre suas } \\
\text { possibilidades. }\end{array}$ \\
\hline $\begin{array}{l}\text { Hein } \\
(2006)\end{array}$ & $\begin{array}{l}\text { De um modo geral, a iniciativa deste trabalho demonstrou boas respostas à melhoria da leitura e } \\
\text { consciência fonológica com a utilização de programa de computador adequado, tornando-se um } \\
\text { recurso importante para o incentivo à leitura de alunos com deficiência mental. }\end{array}$ \\
\hline $\begin{array}{l}\text { Duque } \\
\text { (2008) }\end{array}$ & $\begin{array}{l}\text { O estudo fundamentou-se na ideia de que as relações entre as pessoas, estabelecidas nesse } \\
\text { processo de inclusão, podem ser entendidas como relações de mediação, e esses mediadores } \\
\text { podem ser a família, a escola, os professores, os colegas e o próprio Agente de Inclusão. Foi } \\
\text { possível conhecer as necessidades das famílias, das escolas e do Agente em relação à inclusão } \\
\text { escolar e, assim, entender e instigar possíveis caminhos de trabalho que de fato contribuam com } \\
\text { uma educação inclusiva de qualidade. }\end{array}$ \\
\hline $\begin{array}{l}\text { Oliveira } \\
\text { Capote } \\
(2009)\end{array}$ & $\begin{array}{l}\text { Concluiu-se que a Terapia Assistida por Animais (TAA) traz benefícios às pessoas com } \\
\text { deficiência mental em relação ao desenvolvimento motor, motivação e cuidado com os seres } \\
\text { vivos. }\end{array}$ \\
\hline $\begin{array}{c}\text { Chereguini } \\
\text { (2009) }\end{array}$ & $\begin{array}{l}\text { O presente estudo fornece contribuições em matéria de procedimento e levanta questionamentos } \\
\text { metodológicos que avançam na compreensão do ensino de comportamentos verbais sob controle } \\
\text { de estímulos encobertos para pessoas com atraso no desenvolvimento intelectual. Depreendemos } \\
\text { daí que os erros apresentados pelos participantes podem ser muito mais uma questão de } \\
\text { procedimento do que reflexo das dificuldades de aprendizagem. }\end{array}$ \\
\hline $\begin{array}{l}\text { Faria Lins } \\
\quad(2009)\end{array}$ & $\begin{array}{l}\text { A análise dos dados indicou que: a) as formações implementadas em } 2002 \text { pelo Projeto } \\
\text { Super(Ação) contribuíram para a aceitação da criança com Síndrome de Down por parte dos } \\
\text { professores e para a mudança de práticas pedagógicas consideradas arcaicas por algumas das } \\
\text { entrevistadas; b) a falta de acompanhamento sistemático é o principal entrave para a consolidação } \\
\text { de resultados positivos amplos na rede municipal de ensino de Salvador. Foram identificadas } \\
\text { apenas três crianças com Síndrome de Down matriculadas nas escolas pesquisadas, no entanto a } \\
\text { presença dessas crianças não pode ser atribuída à implementação do Projeto Super(Ação). }\end{array}$ \\
\hline $\begin{array}{c}\text { Luiz } \\
\text { (2009) }\end{array}$ & $\begin{array}{l}\text { Os resultados evidenciaram a necessidade de acompanhamento da família, principalmente das } \\
\text { mães e pais, que permanecem mais próximos do cuidado da criança, antes, durante e após a } \\
\text { inclusão propriamente dita, de modo a apoiá-lós nos momentos de busca e escolha da escola, da } \\
\text { adaptação da criança ao novo ambiente e da transição dos atendimentos oferecidos pela } \\
\text { instituição especializada para outros setores. A articulação entre os setores educacional e da saúde } \\
\text { é crucial, além de um investimento no preparo das escolas e seus recursos humanos para a } \\
\text { recepção dessa clientela. }\end{array}$ \\
\hline
\end{tabular}


Quadro 2 - Resultados das temáticas pesquisadas (continua)

\begin{tabular}{|c|c|}
\hline Autores & Resultados \\
\hline $\begin{array}{c}\text { Gomes de } \\
\text { Sousa } \\
(2011)\end{array}$ & $\begin{array}{l}\text { Os principais achados da pesquisa indicam que as pessoas com deficiência intelectual ainda } \\
\text { sofrem preconceito por serem consideradas incapazes ou frágeis para a execução de um trabalho } \\
\text { em uma empresa, sendo as pessoas com deficiência sensorial ligada à audição e à visão } \\
\text { consideradas preferenciais para ocuparem as vagas oferecidas ao segmento, conforme a legislação } \\
\text { vigente, por possuírem uma qualificação e não representarem um custo maior na adaptação ao } \\
\text { local de trabalho. }\end{array}$ \\
\hline $\begin{array}{c}\text { Macedo } \\
\text { (2011) }\end{array}$ & $\begin{array}{l}\text { Os resultados primeiramente ilustraram que não houve preferência por alimentos calóricos e que } \\
\text { o aumento da magnitude exerceu pouco controle sobre a resposta de escolha dos participantes e } \\
\text { serão considerados como linha-de-base para a continuidade do estudo, em que cada uma das } \\
\text { possíveis variáveis controladoras de escolha alimentar poderão ser introduzidas (e.g., atraso da } \\
\text { contingência reforçadora, custo da resposta). }\end{array}$ \\
\hline $\begin{array}{l}\text { Winter de } \\
\text { Morais } \\
(2011)\end{array}$ & $\begin{array}{l}\text { Os resultados indicaram que a maioria dos profissionais entrevistados se sentia segura para } \\
\text { trabalhar na área de neuropediatria logo após a graduação, realizaram cursos de especialização - } \\
\text { nem sempre na área de neuropediatria - e utilizaram como princípio de tratamento o Conceito } \\
\text { Bobath. Verificamos ainda que a internet é o principal meio utilizado para atualização; que a } \\
\text { família participa do atendimento fisioterapêutico; e que todos consideram importante a interação } \\
\text { entre diversos profissionais. A terapia tem duração aproximada de } 30 \text { minutos e a frequência do } \\
\text { tratamento varia de uma a duas vezes por semana. Sugere-se que os pais, no momento de optar } \\
\text { pelo tratamento, busquem conhecer quais são as experiências dos fisioterapeutas que atenderão } \\
\text { seus filhos e que as instituições incentivem os profissionais para a atualização e busca de uma } \\
\text { especialização adequada visando melhor aproveitamento terapêutico. }\end{array}$ \\
\hline $\begin{array}{c}\text { Carvalho } \\
\text { Mascaro } \\
(2012)\end{array}$ & $\begin{array}{l}\text { A análise dos dados destacou como aspectos relevantes: o desenvolvimento de uma proposta } \\
\text { diferenciada de formação profissional para este alunado, o investimento pessoal da professora em } \\
\text { uma capacitação para aprender a ensinar em um novo contexto, e a iniciativa da escola de buscar } \\
\text { parcerias para implementação de mudanças no seu escopo de atuação enquanto instituição } \\
\text { especializada. A escuta dos alunos, seus familiares e uma profissional da escola colaboraram para } \\
\text { a proposição de novas ações dentro do contexto investigado. Também se evidenciou que as } \\
\text { atividades de aula planejadas pela professora do curso foram determinantes para o bom } \\
\text { desempenho dos alunos, sobretudo por serem realizadas no contexto real em que tais ações se } \\
\text { executam. O trabalho colaborativo da pesquisadora e da professora, viabilizando a elaboração de } \\
\text { um plano individual de acompanhamento para os alunos no treinamento, pode ser apontado como } \\
\text { uma alternativa para o planejamento do processo de transição para a vida pós-escola. Entre outros } \\
\text { aspectos, as entrevistas com os responsáveis indicaram a necessidade de um trabalho mais } \\
\text { pontual da equipe da escola com as famílias sobre a perspectiva de vida pós-escolar dos alunos. }\end{array}$ \\
\hline $\begin{array}{l}\text { Doriqui } \\
\text { (2012) }\end{array}$ & $\begin{array}{l}\text { Foram observados: idade média de } 36 \text { meses, razão entre os sexos masculino e feminino de } 1,2: 1 \text {; } \\
\text { deslocamento periódico para a capital, em } 20 \% \text { dos casos; consanguinidade parental de } 4,5 \% \text {; } \\
\text { casos semelhantes na família em } 7 \% \text {. As mães: maioria entre } 20 \text { e } 34 \text { anos, do lar, com pelo } \\
\text { menos o Ensino Fundamental completo e até duas gestações. Gestação: início do pré-natal até o } \\
\text { terceiro mês em } 63,5 \% \text { (só } 11 \% \text { ainda no primeiro mês); } 14 \% \text { de exposição ao etanol, maioria } \\
\text { nega exposição ao tabaco ou a fármacos impróprios; em } 60 \% \text {, houve intercorrências; em } 17,3 \% \text {, } \\
\text { diagnósticos pré-natais de malformações ou infecções congênitas. Parto: } 88,5 \% \text { em hospital; } 72 \% \\
\text { a termo e } 21,8 \% \text { pré-termos; via vaginal em } 54,5 \% \text { e cesárea em } 35,3 \% \text {; apresentação cefálica em } \\
86 \% \text {. Condições do recém-nato: } 39 \% \text { tem suspeita de hipóxia; } 46,8 \% \text { necessitaram de internação } \\
\text { em UTI e } 44,5 \% \text { estiveram internados por mais de oito dias. Anomalias do Sistema Nervoso } \\
\text { Central (SNC) foram encontradas em } 61,5 \% \text {, incluindo aquelas que puderam ser observadas pela } \\
\text { simples medida de perímetro cefálico - microcefalia (50\%), macrocefalia (5\%). A maioria não } \\
\text { teve acesso aos exames complementares fundamentais à investigação diagnóstica (imagem de } \\
\text { SNC, cariótipo, avaliação auditiva e oftalmológica). }\end{array}$ \\
\hline
\end{tabular}


Quadro 2 - Resultados das temáticas pesquisadas (conclusão)

\begin{tabular}{|c|l|}
\hline Autores & \multicolumn{1}{|c|}{ Resultados } \\
\hline $\begin{array}{c}\text { Silva } \\
(2012)\end{array}$ & $\begin{array}{l}\text { Os resultados demonstraram que, para a avaliação de crianças e adolescentes com Síndrome de } \\
\text { Down quanto ao seu crescimento, são recomendadas curvas próprias para um referencial da } \\
\text { população brasileira, já que carecemos de dados específicos para a população em questão. }\end{array}$ \\
\hline $\begin{array}{c}\text { Comin } \\
(2013)\end{array}$ & $\begin{array}{l}\text { Foi possível concluir que atividades estruturadas favoreceram o aprendizado da leitura e escrita } \\
\text { de jovens com Síndrome de Down, visto que as estimulações de leitura e escrita partiram sempre } \\
\text { de atividades concretas e/ou adaptadas. }\end{array}$ \\
\hline $\begin{array}{c}\text { Rezende } \\
(2013)\end{array}$ & $\begin{array}{l}\text { Os resultados demonstraram que o desempenho funcional de crianças com Síndrome de Down } \\
\text { (SD) referentes às habilidades funcionais e assistência do cuidador foram diferentes para as } \\
\text { diferentes faixas (grupos) etários [...]. Observamos que, em relação ao nível de satisfação com o } \\
\text { suporte social, os cuidadores em sua maioria estão insatisfeitos com o suporte social recebido. } \\
\text { Para os indicadores dos domínios que compõem o índice de qualidade de vida, a correlação mais } \\
\text { elevada encontrada foi entre o domínio social e o psicológico do indicador de qualidade de vida. } \\
\text { A pesquisa observou uma correlação negativa entre a maioria dos indicadores de qualidade de } \\
\text { vida e o nível socioeconômico e grau de instrução, ou seja, pode ser dito que foi notada uma } \\
\text { qualidade de vida inferior para piores níveis socioeconômicos, principalmente considerando-se o } \\
\text { domínio ambiental. Observou-se ainda que nos níveis socioeconômicos piores o grau de instrução } \\
\text { é menor. }\end{array}$ \\
\hline $\begin{array}{c}\text { Dota } \\
\text { (2015) }\end{array}$ & $\begin{array}{l}\text { Os resultados indicaram que as médias do pico máximo de aceleração são menores para o Grupo } \\
\text { Erofissionalmente produtivas quando capacitadas e que esta experiência melhora sua autonomia e } \\
\text { suas relações sociais. }\end{array}$ \\
\hline $\begin{array}{l}\text { Vianna } \\
\text { obteve média superior ao grupo das meninas, tanto para o Grupo Controle (GC) como para o } \\
\text { GSD. }\end{array}$ \\
\hline
\end{tabular}

Fonte: Elaborado pelos autores com dados recolhidos em BDTD/IBICT (2015).

O resumo que apresentamos dos resultados estão articulados às temáticas das pesquisas (Tabela 3). Os resultados mostram que as concepções e representação da pessoa com deficiência são atravessadas pelo preconceito e pela estigmatização no trabalho, principalmente no caso das pessoas com deficiência intelectual. O domínio da leitura e da escrita consistem em habilidades que podem ser desenvolvidas por programas de computadores ou também por meio de atividades estruturadas. Na implementação da proposta de inclusão escolar, o Agente de Inclusão e a família são mediadores fundamentais, sendo fundamental também o acompanhamento sistemático e formativo nesse processo. Necessidade constatada em revisão de literatura sobre a inclusão escolar de crianças com Síndrome de Down (LUIZ et al., 2008).

Os estudos expõem que o trabalho colaborativo entre os profissionais da instituição, da empresa e da família colabora na qualificação da pessoa com deficiência para o mercado de trabalho. A inclusão social pode ser possível quando existe um plano individual de acompanhamento como alternativa para o planejamento do processo de transição para a vida pós-escola. O desenvolvimento de um programa 
de capacitação profissional pode incentivar a autoestima e o autoconceito. Inclusive, Dota (2015) diz que, após esse programa ter sido cumprido, foi identificado o aumento de participação social da pessoa com deficiência intelectual e a diminuição de necessidades de apoio. Ou seja, quando esse público é capacitado, pode se tornar mais produtivo, ter elevação da autoestima e melhora nas relações sociais. Isto requer qualificação do professor, para que seja mediador no processo educacional (LUIZ et al., 2008).

Os serviços de instituições especializadas contribuem no desenvolvimento global da pessoa com deficiência e na melhoria de sua qualidade de vida. Essa melhoria pode ocorrer por meio de medidas como: Terapia Assistida por Animais, para ajudar pessoas com deficiência mental no desenvolvimento motor e na sociabilidade; programas de delineamento experimental que colaboram na aquisição de comportamentos verbais e de uma alimentação saudável; do trabalho de fisioterapeutas, especialistas em neuropediatria e a interação com a família; jogos de videogames que simulam boliche e golfe, que auxiliam na medida da aceleração do comportamento motor; da revisão das formas de avaliação do crescimento de crianças e adolescentes com Síndrome de Down; de um maior suporte social aos cuidadores em seu trabalho; da qualificação permanente dos profissionais da saúde com relação à assistência pré-natal e ao parto. São imprescindíveis políticas públicas que melhorem as condições socioeconômicas e graus de instrução da família para apresentar aumento nos indicadores de qualidade de vida da pessoa com deficiência intelectual, bem como a implementação efetiva e urgente da Política Nacional de Atenção Integral em Genética Clínica (DORIQUI; 2012; REZENDE, 2013; SILVA; 2012).

Dessa forma, evidenciamos que os serviços prestados pelas instituições especializadas perpassam diferentes dimensões da vida humana, a saber: a educação, o trabalho, a saúde e a assistência social. Porém, qual seria o papel dessas instituições para o lazer e para a cultura? Os estudos não alvitraram as possibilidades de oferecer lazer e cultura na instituição, considerando a inclusão social. Vygotski (1997) reflete que a visão negativa da deficiência limita o acesso à cultura pelas pessoas, que são pensadas como tendo "defeito". Afeta também a forma de organizar e oportunizar o ensino-aprendizagem e, consequentemente, não garante a aquisição do saber sistematizado. O pensador russo ajuda-nos a repensar a Educação Especial, que deve apostar nas possibilidades do sujeito e no seu desenvolvimento de forma qualitativamente distinta, assegurando que a pessoa com deficiência pode aprender como as demais, desde que se considere sua organização psíquica diferenciada e que se oportunizem o aprendizado e a assimilação da cultura (VYGOTSKI, 1997). 


\section{Considerações Finais}

A produção acadêmica das instituições especializadas para a pessoa com deficiência intelectual mostra que os pesquisadores da área trouxeram diferentes objetos de estudos, objetivos e métodos. As condições de produção dessas pesquisas estão relacionadas aos fatores biopsicossociais, políticos e educacionais que o público em questão lida no seu cotidiano. O fator biopsicossocial, em especial, é determinante nas investigações.

A presente investigação elucida a história da referida produção acadêmica apoiando-se em indicadores bibliométricos para caracterizar os estudos. As pesquisas sobre as instituições especializadas para as pessoas com deficiência intelectual disponíveis na BDTD/IBICT evidenciam a diversidade de temas relacionados às várias dimensões da vida e às necessidades imediatas do público assistido. O foco principal é a melhoria da qualidade de vida e formação para o trabalho, por meio das quais as instituições especializadas são reconhecidas pela sua relevância social. Porém o foco das pesquisas sinaliza a permanência do status quo das pessoas com deficiência intelectual, representadas e enfatizadas por suas "incapacidades" e ajustamentos à sociedade. Por que não há pesquisas que se propõem a estudar como ocorre o desenvolvimento educacional dos assistidos pelas instituições privadas-assistenciais?

Os resultados da pesquisa também trazem à baila questionamentos sobre a proposta educacional das instituições especializadas, tendo presente que elas recebem recursos públicos para desenvolver serviços de assistência à saúde, à educação, ao trabalho. As pesquisas analisadas não apresentaram as propostas pedagógicas das instituições. Somente Rojas (1996) e Rodrigues (1998) problematizaram o conceito de deficiência mental e os serviços ofertados na instituição. Nenhum trabalho tomou como objeto de estudo a instituição especializada em seus aspectos político-pedagógicos. Novos estudos podem ser empreendidos, tendo por objetivo refletir sobre uma formação educacional para a pessoa com deficiência intelectual que lhe garanta a aquisição dos conhecimentos científicos, filosóficos e artísticos.

\section{Notas}

${ }^{1}$ Optou-se por manter o plural no masculino, conforme regra padrão da língua portuguesa. No entanto, vale frisar que a maioria dos trabalhos analisados no presente artigo são de autoras e orientadoras, o que ratifica os argumentos de Rigolin, Hayashi e Hayashi (2013) de que, na área do conhecimento da Educação, ocorre o processo de feminização da ciência. 


\section{REFERÊNCIAS}

BARBOSA, A. J. G.; MOREIRA, P. de S. Deficiência mental e inclusão escolar: produção científica em Educação e Psicologia. Revista Brasileira de Educação Especial, Marília, v. 15, n. 2, p. 337-352, maio/ago. 2009.

BELLO, S.F., PIZZANI, L., HAYASHI, M.C.P.I. Análise de redes de autoria e coautoria científica em Fonoaudiologia e Educação Especial. In: HAYASHI, Maria C. P. I.; FARIA, Leandro I. L.; HAYASHI, Carlos R. M. (Org.). Bibliometria e cientometria: estudos temáticos. São Carlos: Pedro e João Editores, 2013. p. 145-159.

BRASIL. Decreto n. 7.611, de 17 de novembro de 2011. Dispõe sobre a educação especial, o atendimento educacional especializado e dá outras providências. Texto original. Diário Oficial [da] República Federativa do Brasil, Poder Executivo, Brasília, DF, 18 nov. 2011, p. 5, edição extra e republicado por ter saído com incorreção no DOU no 221, de 18 nov. 2011, seção, 1, p. 12.

. Política Nacional de Educação Especial na perspectiva da educação inclusiva. Brasília, DF: MEC/SEESP, 2008.

BUENO, J. G. S. Deficiência e ensino superior: balanço das dissertações e teses brasileiras (1987/2006). In: SEMINÁRIO CAPIXABA DE EDUCAÇÃO INCLUSIVA, 11. Vitória, ES, 15 a 18 set. 2008. Anais eletrônicos... Vitória: UFES, 2008. p. 100-112. Disponível em: $<$ http://www.forumcapixaba-ei.com.br/pdf/anais-xi-seminario-capixaba-de-educacao-inclusiva-2008. pdf>. Acesso em: 18 set. 2017.

CARROGI-VIANNA, D. Análise de medidas de aceleração do movimento na prática de jogos virtuais em adolescentes com síndrome de Down. 2013. 89f. Dissertação (Mestrado em Distúrbios do Desenvolvimento) - Centro de Ciências Biológicas e da Saúde, Universidade Presbiteriana Mackenzie, São Paulo, 2013.

CARVALHO MASCARO, C. A. A. de. Capacitação de pessoas com deficiência intelectual: estudo de caso de um curso de Educação Profissional. 2012. 116f. Dissertação (Mestrado em Educação) Faculdade de Educação, Universidade do Estado do Rio de Janeiro, Rio de Janeiro, 2012.

CELlARD, A. A análise documental. In: POUPART, J. et al. A Pesquisa Qualitativa: enfoques epistemológicos e metodológicos. 2. ed. Petrópolis: Vozes, 2010. p. 295-315.

CHEREGUINI, P. A. C. Comportamento verbal sob controle de estímulos encobertos em indivíduos com atraso no desenvolvimento intelectual: estudos exploratórios. 2009. 114f. Dissertação (Mestrado em Educação Especial) - Centro de Educação e Ciências Humanas, Universidade Federal de São Carlos, São Carlos, 2009.

COMIN, B. C. Atividades estimuladoras de leitura e escrita em estudantes com síndrome de Down. 2013. 285 f. Dissertação (Mestrado em Educação Especial) - Centro de Educação e Ciências Humanas, Universidade Federal de São Carlos, São Carlos, 2013. 
D’ANTINO, M. E. F. A máscara e o rosto da instituição especializada: marcas que o passado abriga e o presente esconde. São Paulo: Memnon, 1998.

DORIQUI, M. J. R. Avaliação clínico-epidemiológica de crianças e adolescentes com atraso global do desenvolvimento atendidos em serviço especializado de genética médica, São Luís-MA. 2012. $110 \mathrm{f}$. Dissertação (Mestrado em Saúde Materno-Infantil) - Universidade Federal do Maranhão, São Luís, 2012.

DOTA, F. P. Inclusão da pessoa com deficiência intelectual no mercado de trabalho: avaliação de um programa de capacitação profissional. 2015. 83f. Dissertação (Mestrado em Psicologia do Desenvolvimento e Aprendizagem) - Faculdade de Ciências, Universidade Estadual Paulista, Bauru, 2015.

DUQUE, L. F. O agente de inclusão escolar no apoio a alunos com deficiência intelectual: um estudo em escolas municipais de São Paulo. 2008. 162f. Dissertação (Mestrado em Distúrbios do Desenvolvimento) - Centro de Ciências Biológicas e da Saúde, Universidade Presbiteriana Mackenzie, São Paulo, 2008.

FARIA LINS, A. M. de. Políticas públicas para a inclusão de crianças com síndrome de Down no ensino regular: um estudo sobre o Projeto Super(Ação). 2009. 126f. Dissertação (Mestrado em Políticas Sociais e Cidadania) - Superintendência de Pesquisa e Pós-Graduação, Universidade Católica do Salvador, Salvador, 2009.

FEDERAÇÃO NACIONAL DAS APAES (FENAPAES). Posicionamento do movimento apaeano em defesa da inclusão escolar de pessoas com deficiências intelectual e múltipla. Brasília, DF: Fenapaes, 2007.

Revista Mensagem da Apae, Edição Especial - 60 anos. Brasília, DF, ano 47, n. 1, nov. 2014. 131p. Disponível em: <http://apaebrasil.org.br/uploads/Revista_60_anos_-_Rumo_a_Final_ BAIXA_RESOLUCAO_(1).pdf>. Acesso em: 18 set. 2017.

Relatório de Atividades - 2014. Brasília, DF: Fenapaes, 2015.

Federação Nacional das Apaes. Brasília, DF: Fenapaes, 2016. (Cartilha).

FEDERAÇÃO NACIONAL DAS ASSOCIAÇÕES PESTALOZZI (FENAPESTALOZZI). Associações Pestalozzi. Disponível em: <http://www.fenapestalozzi.org.br/associacoes-pestalozzi>. Acesso em: 10 dez. 2015.

GATTI, B. A. Implicações e Perspectiva da Pesquisa Educacional no Brasil Contemporâneo. Cadernos de Pesquisa, São Paulo, Fundação Carlos Chagas, n. 113, p. 65-81, jul. 2001.

GOMES SOUSA, C. H. Pessoa com deficiência intelectual: Desafios para inclusão nas empresas de grande porte do Pólo Industrial de Manaus/AM. 2011. 140f. Dissertação (Mestrado em Serviço Social) - Centro de Ciências Sociais, Pontifícia Universidade Católica do Rio de Janeiro, Rio de Janeiro, 2011.

HAYASHI, M. C. P. I. H. Análise bibliométrica: leituras teóricas, procedimentos metodológicos e protocolo de coleta de dados. São Carlos, 2014. (mimeo). 
HAYASHI, M. C. P. I. H; HAYASHI, C. R. M.; MARTINEZ, C. M. S. Estudos sobre jovens e juventude: diferentes percursos refletidos na produção científica brasileira. Educação, Sociedade \& Culturas, Lisboa, Universidade do Porto, n. 27, p. 131-154, 2008.

HEIN, J. M. Leitura e Consciência Fonológica da deficiência mental: intervenções com o programa de "Alfabetização Fônica Computadorizada". 2006. 83f. Dissertação (Mestrado em Distúrbios do Desenvolvimento) - Centro de Ciências Biológicas e da Saúde, Universidade Presbiteriana Mackenzie, São Paulo, 2006.

INSTITUTO BRASILEIRO DE INFORMAÇÃO EM CIÊNCIA E TECNOLOGIA. Biblioteca Digital de Teses e Dissertações. Disponível: <http://bdtd.ibict.br/vufind/>. Acesso em: 2 nov. 2015.

JANNUZZI, G. de M.; CAIADO, K. R. M. APAE: 1954 a 2011 - algumas reflexões. Campinas, SP: Autores Associados, 2013.

LUIZ, F. M. R. et al. A inclusão da criança com síndrome de Down na rede regular de ensino: desafios e possibilidades. Revista Brasileira de Educação Especial, Marília, v. 14, n. 3, p. 497-508, set./dez. 2008.

LUIZ, F. M. R. Experiências de famílias de crianças com síndrome de Down no processo de inclusão na rede regular de ensino. 2009. 116f. Dissertação (Mestrado) - Escola de Enfermagem de Ribeirão Preto, Universidade de São Paulo, Ribeirão Preto, 2009.

MACEDO, M. Z. Escolha e preferência por alimentos com ou sem valores calóricos em crianças com deficiência intelectual e sobrepeso. 2011. 61f. Dissertação (Mestrado em Psicologia) - Centro de Educação e Ciências Humanas, Universidade Federal de São Carlos, São Carlos, 2011.

MARTINS, M. F. Uma "catarsis" no conceito de cidadania: do cidadão cliente à cidadania com valor ético-político. Revista Ética, Campinas, v. 2, n. 2, p. 106-118, jul./dez. 2000.

MARTINS, M. F; GROPPO, L. A. Sociedade Civil e Educação: fundamentos e tramas. Campinas, SP: Autores Associados; Americana, SP: UNISAL, 2010.

MELO, D. C. F. de; SILVA, J. H. As políticas públicas da educação especial e a FENAPAES sob a perspectiva gramsciana. Revista Ibero-Americana de Estudos em Educação, Araraquara, v. 11, n. 1, p. 151-164, 2016.

OLIVEIRA CAPOTE, P. S. de. Terapia assistida por animais e deficiência mental: análise do desenvolvimento psicomotor. 2009. 204f. Dissertação (Mestrado em Educação Especial) - Centro de Educação e Ciências Humanas, Universidade Federal de São Carlos, São Carlos, 2009.

PEREIRA, M. A.; JUNIOR, A. F.; HAYASHI, M. C. P. I. Os Institutos Históricos e Geográficos no Brasil: estudo bibliométrico no banco de teses da CAPES. In: HAYASHI, M. C. P. I.; FARIA, L. I. L.; HAYASHI, C. R. M. (Org.). Bibliometria e cientometria: estudos temáticos. São Carlos: Pedro e João Editores, 2013. p. 229-246. 
PLATAFORMA SUCUPIRA. Dados quantitativos de programas recomendados e reconhecidos Capes. Disponível em: <https://sucupira.capes.gov.br/sucupira/public/consultas/coleta/programa/quanti tativos/quantitativoRegiao.jsf>. Acesso em: 26 abr. 2017.

RAFANTE, H. C. Helena Antipoff, as sociedades Pestalozzi e a Educação Especial no Brasil. 2011. 309 f. Tese (Doutorado em Educação) - Centro de Educação e Ciências Humanas, Universidade Federal de São Carlos, São Carlos, 2011.

REZENDE, L. K. Desempenho funcional na Síndrome de Down: relações com o suporte social e qualidade de vida de seus cuidadores. 2013. 127f. Tese (Doutorado em Distúrbios do Desenvolvimento) - Centro de Ciências Biológicas e da Saúde, Universidade Presbiteriana Mackenzie, São Paulo, 2013.

RIGOLIN, C. C. D.; HAYASHI, C. R. M.; HAYASHI, M. C. P. I. Métricas da participação feminina na ciência e na tecnologia no contexto dos INCTs: primeiras aproximações. Liinc em Revista, Rio de Janeiro, v. 9, p. 143-170, 2013.

RODRIGUES, J. L. Aspectos de formação e transição em programas para adolescentes e adultos portadores de deficiência mental em instituições especializadas. 1998. 282f. Tese (Doutorado em Educação Física) - Faculdade de Educação Física, Universidade Estadual de Campinas, Campinas, 1998.

ROJAS, M. F. Avaliação do conceito de pessoa deficiente mental adulta mediante depoimentos de profissionais atuantes em instituições especializadas na região de Campinas-SP. 1996. $137 \mathrm{f}$. Dissertação (Mestrado em Educação) - Faculdade de Educação, Universidade Estadual de Campinas, Campinas, 1996.

SACARDO, M. S. Estudo bibliométrico e epistemológico da produção científica em Educação Física na Região Centro-Oeste do Brasil. 2012. 255f. Tese (Doutorado em Educação Especial) - Programa de Pós-Graduação em Educação Especial, Universidade Federal de São Carlos, São Carlos, 2012.

SIEMS MARCONDES, M. E. R. Educação Especial em Roraima: História, Política e Memória. 2013. 359f. Tese (Doutorado em Educação Especial) - Centro de Educação e Ciência Humanas, Universidade Federal de São Carlos, São Carlos, 2013.

SILVA, F. F. da. Crescimento da pessoa com Síndrome de Down: contribuição para a construção de um referencial. 2012. 85f. Dissertação (Mestrado em Educação Física) - Faculdade de Educação Física, Universidade Estadual de Campinas, Campinas, 2012.

SILVA, M. R. da. Análise bibliométrica da produção científica docente do Programa de PósGraduação em Educação Especial da UFSCar: 1998-2003. 2004. 177f. Dissertação (Mestrado em Educação Especial) - Universidade Federal de São Carlos, 2004.

; HAYASHI, C. R. M.; HAYASHI, M. C. P. I. Análise bibliométrica e cientométrica: desafios para especialistas que atuam no campo. InCID: Revista de Ciência da Informação e Documentação, Ribeirão Preto, USP, v. 2, p. 110-129, 2011. 
SILVA, R. H. dos R.; GAMBOA, S. S. Análise epistemológica da pesquisa em educação especial: a construção de um instrumental de análise. Atos de pesquisa em educação, Universidade Regional de Blumenau, v. 6, n. 2, p. 373-402, maio/ago. 2011.

STEINER, J. E. Qualidade e diversidade institucional na pós-graduação brasileira. Estudos Avançados, São Paulo, v. 19, n. 54, p. 341-365, ago. 2005.

THAMSTEN, F. (Org.). Lizair Guarino: lutas e conquistas pela cidadania. Niterói, RJ: Nota Bene Editora, 1999.

UNIVERSIDADE PRESBITERIANA MACKENZIE. Área de concentração. Disponível em: $<$ http://up.mackenzie.br/stricto-sensu/disturbios-do-desenvolvimento/area-de-concentracao-e-linhas-depesquisa/>. Acesso: 11 nov. 2015.

VYGOTSKI, L. S. Obras Escogidas V-Fundamentos de defectología. Madrid: Aprendisaje Visor, 1997.

WINTER DE MORAIS, K. D. Perfil do atendimento fisioterapêutico às crianças com Síndrome de Down até os três anos de idade em instituições especializadas. 2011. 68f. Dissertação (Mestrado em Distúrbios do Desenvolvimento) - Centro de Ciências Biológicas e da Saúde, Universidade Presbiteriana Mackenzie, São Paulo, 2011. 


\author{
Knowledge production about specialized \\ institutions for persons with intellectual \\ disabilities (1996-2015)
}

\begin{abstract}
The present paper analyses the scientific academic production about specialized institutions for persons with intellectual disabilities in format of theses and dissertations available at the Brazilian Digital Library of Theses and Dissertations (BDTD) from the Brazilian Institute of Information in Science and Technology (IBICT). This is a qualitative and quantitative study, and a bibliometric, methodological and content analysis approach, done in three steps: theoretical and methodological preparation; data collection and registration; summary and analysis of results. The results showed the existence of 18 works about the researched subject, with a majority with a master's degree, between the years of 1996 and 2015. The studies belong to 9 different Higher Education Institutions, most of them located in the Southeast Region, with a significant participation of the Mackenzie Presbyterian University (Mackenzie) and the Federal University of São Carlos (UFSCar) through their corresponding Development Disorders and Special Education graduate programs. These papers mainly deal with subjects such as the person with disability's quality of life and the education for life and work, developed within the specialized institutions. Predominate qualitative approaches with qualitatives of behavioral theory, based on instruments such as interviews and scales. Therefore, the mapping of researches demonstrates that few works used their own specialized institutions for persons with intellectual disability as an object of study even though these works contemplate issues like health, work, education and assistance. However, we do not find researches that problematizes, among others aspects: the role of special schools assumed by the institutions; the right to schooling of the disabled person; the publicprivate relationship that constitutes the offer of services of philanthropic and non-public nature.
\end{abstract}

Keywords: Specialized institution. Knowledge production. Special Education. Intellectual disability.
Producción del conocimento sobre las instuciones especializadas para las personas com discapacidad intelectual (1996-2015)

\section{Resumen}

En este artículo se analiza la producción científica académica en forma de tesis y dissertações sobre el tema de las instituciones especializadas para las personas minusválidos intelectuales/mentales, disponibles en la Biblioteca digital de Tesis y Disertaciones (BDTD) do IBICT. Es un estudio cualitativo y cuantitativo de enfoque metodológica bibliométrica y análisis de contenido, realizados en tres etapas: preparación teórica e metodológica, recopilación y registro de datos, sistematización y análisis de los resultados. Los resultados muestran que existen 18 investigaciones sobre el tema investigado, la mayoría en nivel de maestría, entre los años 1996 a 2015. Los estudios pertenecen a 9 diferentes instituciones de enseñanza superior, sobre todo en la Región Sureste y con significativa participación de la Universidad Mackenzie (Mackenzie) y de la Universidad Federal de São Carlos (UFSCar), articuladas en sus respectivos programas de postgrado: Trastornos de desarrollo y Educación Especial. Los trabajos tratan principalmente sobre temas de la calidad de vida de las personas con discapacidad y la formación para el trabajo y para la vida, desarrolladas en las propias instituciones especializadas. Predominan los enfoques cualitativos con fundamentos de la teoría del comportamiento, con base en los instrumentos de entrevistas y escalas, entre otros. Por lo tanto, los estudios del mapeo evidencian pocas investigaciones que se centran en la propia institución especialiciada para la persona minusválida intelectual como objeto de estudio, a pesar, de los trabajos contemplar las dimensiones de la salud, del trabajo, de la educación y de la asistencia. Sin embargo, no se encontraron estudios que problematizan, entre otros: el papel de la escuela especial que toman las instituciones; el derecho a la educación de las personas con discapacidad; la relación público-privada es la prestación de servicios en filantrópica y no pública.

Palabras clave: Institución especializada. La producción de conocimiento. La educación especial. La discapacidad intelectual. 
João Henrique da Silva

E-mail: jhsilvamg@icloud.com

Míriam Elena Cesar Almeida

E-mail: miriamelena_almeida@hotmail.com
Enviado em: 07/04/2016

Versão final recebida em: 01-04-2017

Aprovado em: 07/05/2017

\section{Kátia Regina Moreno Caiado}

E-mail: caiado.katia@ufscar.br 